\title{
Carbon Metabolism and Bacteroid Functioning Are Involved in the Regulation of Nitrogen Fixation in Medicago truncatula Under Drought and Recovery
}

\author{
Estíbaliz Larrainzar, ${ }^{1}$ Stefanie Wienkoop, ${ }^{2}$ Christian Scherling, ${ }^{3}$ Stefan Kempa, ${ }^{3}$ Rubén Ladrera, ${ }^{1}$ \\ Cesar Arrese-Igor, ${ }^{1}$ Wolfram Weckwerth, ${ }^{2}$ and Esther M. González ${ }^{1}$ \\ ${ }^{1}$ Dpto. Ciencias del Medio Natural, Universidad Pública de Navarra, 31006 Pamplona, Spain; ${ }^{2}$ Department of Molecular \\ Systems Biology, University of Vienna, 1090 Vienna, Austria; ${ }^{3}$ Max Planck Institute of Molecular Plant Physiology, 14424 \\ Potsdam-Golm, Germany
}

Submitted 7 April 2009. Accepted 27 July 2009.

\begin{abstract}
Regulation of symbiotic nitrogen fixation (SNF) during drought stress is complex and not yet fully understood. In the present work, the involvement of nodule $\mathrm{C}$ and $\mathrm{N}$ metabolism in the regulation of SNF in Medicago truncatula under drought and a subsequent rewatering treatment was analyzed using a combination of metabolomic and proteomic approaches. Drought induced a reduction of SNF rates and major changes in the metabolic profile of nodules, mostly an accumulation of amino acids (Pro, His, and Trp) and carbohydrates (sucrose, galactinol, raffinose, and trehalose). This accumulation was coincidental with a decline in the levels of bacteroid proteins involved in SNF and C metabolism, along with a partial reduction of the levels of plant sucrose synthase 1 (SuSy1). In contrast, the variations in enzymes related to $\mathrm{N}$ assimilation were found not to correlate with the reduction in SNF, suggesting that these enzymes do not have a role in the regulation of SNF. Unlike the situation in other legumes such as pea and soybean, the drought-induced inhibition of SNF in M. truncatula appears to be caused by impairment of bacteroid metabolism and $\mathrm{N}_{2}$-fixing capacity rather than a limitation of respiratory substrate.
\end{abstract}

Grain and forage legumes are important crops in agriculture, accounting for $27 \%$ of the world's primary crop production (Graham and Vance 2003). One of their main characteristics is the ability to establish symbiotic relations with $\mathrm{N}_{2-}$ fixing soil bacteria. Despite the numerous agronomical and environmental advantages of legumes, their production is limited by abiotic stresses, particularly drought (Sprent 2001). In nodulated legumes, water deficit negatively affects the growth of the host plant and endosymbiotic nodule bacteria as well as symbiotic nitrogen fixation (SNF) capacity (Zahran 1999).

Corresponding authors: E. M. González; Telephone: +34 948 168412; Fax: +34 948 168930; E-mail: esther.gonzalez@unavarra.es; and S. Wienkoop; Telephone: +43 1427757703 ; Fax +43 1427 79577; E-mail: stefanie.wienkoop@univie.ac.at

E. Larrainzar and S. Wienkoop contributed equally to this work.

*The $\boldsymbol{e}$-Xtra logo stands for "electronic extra" and indicates that four supplementary tables are published online and also that Figure 5 appears in color online.
The regulation of SNF under drought stress involves a number of factors (namely, internal $\mathrm{O}_{2}$ availability, $\mathrm{N}$ feedback regulation, and $\mathrm{C}$ limitation) whose interactions are not fully understood. Limitation of nodule permeability to $\mathrm{O}_{2}$, via the regulation of the $\mathrm{O}_{2}$ diffusion barrier (Denison 1998), was initially suggested to be the cause of the inhibition of SNF under drought (Durand et al. 1987; Hunt and Layzell 1993). However, later studies showed that changes in nodule permeability were the effect, and not the cause, of the inhibition of nodule metabolism (Del Castillo et al. 1994; Del Castillo and Layzell 1995). In addition to this, the $\mathrm{N}$ status of the plant has been suggested to regulate SNF via an N-feedback regulation. Numerous molecules, including ureides, glutamine, and asparagine, have been proposed to act as signals in shoots or nodules in different legume species (Atkins et al. 1992; Bacanamwo and Harper 1997; Neo and Layzell 1997; Serraj et al. 1999; Vadez et al. 2000; Ladrera et al. 2007). However, to date, a clear candidate has not been found. Regulation of SNF has also been related to a reduced C supply, mostly in the form of malate, for bacteroid respiration (Arrese-Igor et al. 1999), due to the downregulation of one of the enzymes responsible for the cleavage of sucrose in nodules: sucrose synthase (SuSy). The connection between inhibition of SNF and nodule C limitation has been experimentally demonstrated for both temperate (González et al. 1998; Gordon et al. 1999; Gálvez et al. 2005) and tropical grain legumes (González et al. 1995; Ramos et al. 1999). Nevertheless, recent data obtained in alfalfa (Naya et al. 2007) and in M. truncatula (R. Ladrera, E. M. González, and C. ArreseIgor, unpublished data) have challenged this model, suggesting that alternative mechanisms may be involved in the regulation of SNF of pasture legumes under drought. In an initial proteomic analysis, the nodule plant proteome was profiled, and $\mathrm{C}, \mathrm{N}$, and $\mathrm{S}$ metabolisms were suggested to be involved in the response of $M$. truncatula under a water-deficit situation (Larrainzar et al. 2007).

In the present work, we employ a combination of metabolomic and proteomic approaches, including both relative and novel, absolute protein quantification techniques, to analyze the effect of drought stress and subsequent rewatering in M. truncatula plants at the nodule level. The major objectives addressed are to i) analyze the involvement of nodule $\mathrm{C}$ and $\mathrm{N}$ metabolism in the regulation of SNF in M. truncatula during the initial stages of drought and ii) gain further insights into the metabolic and proteomic responses triggered by a shortterm rewatering treatment. 


\section{RESULTS}

Physiological characterization of plants subjected to drought and a subsequent recovery treatment.

Plant water status during the different treatments was monitored by measuring leaf and nodule water potentials $\left(\psi_{\mathrm{w}}\right)$. Because both parameters responded similarly, only nodule measurements are presented here (Fig. 1A). Nodule $\psi_{\mathrm{w}}$ declined gradually throughout the drought period, reaching values of $-2.11 \pm 0.18 \mathrm{MPa}$ during severe drought (D6), while the control plant maintained values of $-0.55 \pm 0.10 \mathrm{MPa}$. A 2-day rehydration period allowed nodule water potential of severely drought-stressed plants to recover to control values. The effect of drought on SNF was evaluated as apparent nitrogenase activity (ANA), based on $\mathrm{H}_{2}$ evolution of intact plants (Fig. 1B). Plants under mild drought (D3) showed a reduction of $38 \%$ ANA when compared with control plants, reaching a $76 \%$ reduction under more severe conditions. Rewatering was translated into a partial recovery of SNF capacity (52\% reduction
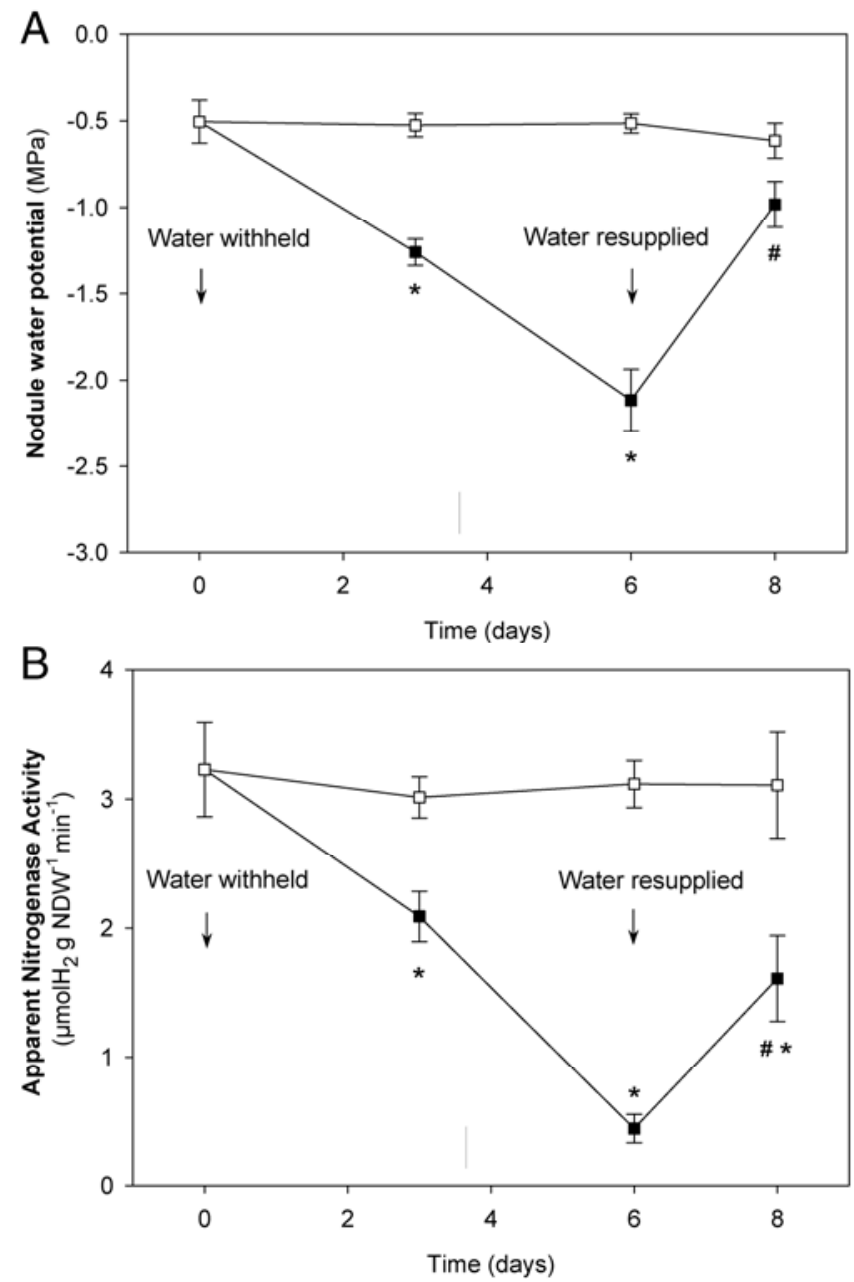

Fig. 1. A, Effect of drought stress and rewatering on nodule water potential and $\mathbf{B}$, symbiotic nitrogen fixation as measured by apparent nitrogenase activity in Medicago truncatula plants. Nodule samples were harvested at four time points, namely: beginning of the treatment (day 0), mild drought (day 3), severe drought (day 6), and after 2 days of rewatering (day 8). In parallel, nodules from plants grown under control conditions were collected. Measurements from control plants are represented as open squares $(\square)$ and from drought and recovery plants as closed squares (ם). Values are the mean \pm standard error of three biological replicates. For each treatment, an asterisk (*) represents significant differences with the corresponding control value at $\alpha=0.05$. Significant differences between recovered samples and severe drought samples at $\alpha=0.05$ are indicated with a hash (\#). compared with control plants), which was significantly greater than that of severe drought-stressed plants. This intermediate situation was particularly useful for the analysis of the early changes occurring during the reestablishment of an active $\mathrm{N}_{2-}$ fixation process. After physiological characterization, metabolomic and proteomic analyses of root nodules were carried out, as schematically represented in Figure 2.

\section{Effect of drought and recovery on the metabolite profiles of M. truncatula root nodules.}

M. truncatula nodule samples were subjected to metabolite profiling by gas chromatography coupled to time-of-flight mass spectrometry (GC-TOF-MS), which led to the identification and dry-matter-based quantification of 66 compounds, mostly corresponding to amino acids $(40.6 \%$ of total metabolites detected), carbohydrates (15.6\%), organic acids $(23.4 \%)$, and polyols $(9.4 \%)$. Due to the extraction method, the entire nodule tissue was used, resulting in a metabolite pool with a contribution from both symbiotic partners. The complete metabolite dataset together with the experimental Metabolomics Standards Initiative compliant metadata (Fiehn et al. 2007, 2008; Sumner et al. 2007) are provided as online supplemental material (Supplementary Tables S1 and S2).

The total set of metabolites was subjected to hierarchical clustering analysis (HCL), which allowed the grouping of metabolites into at least four categories: i) metabolites such as neutral sugars, polyols, and amino acids, which accumulated during drought and then returned to control values after recovery; ii) metabolites such as citrulline, ribose, adenine, and uracil, which accumulated under drought and only partially returned to control values upon rehydration; iii) metabolites not showing a clear trend during drought but whose content declined in recovery samples, including dehydroascorbic and pyruvic acid, together with glucose- and fructose-6-P; and iv) metabolites not showing any clear response during the experiment (e.g., citric and aspartic acid) (Fig. 3A). For a detailed evaluation of the effect of drought and recovery on the meta-

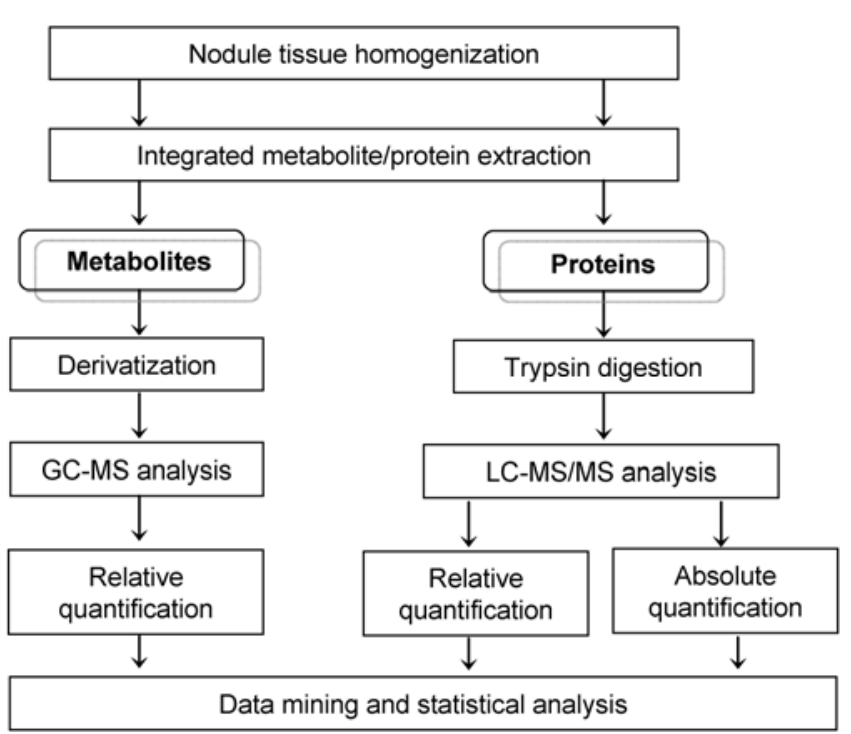

Fig. 2. Schematic representation of the experimental workflow. Integrated extraction of proteins and metabolites was carried out accordingly to Morgenthal and associates (2007). Metabolites were separated based on their hydrophobicity and gas chromatography coupled to time-of-flight mass spectrometry (GC-TOF-MS) analysis of the polar phase was performed. In parallel, proteins were isolated, trypsin digested, and analyzed via gel-free liquid chromatography tandem mass spectrometry (LCMS/MS) approaches. Relative and absolute protein quantifications were made as previously described (Wienkoop and Weckwerth 2006; Wienkoop et al. 2008). 
bolic profiles of $M$. truncatula nodules, pairwise comparisons between control and treated samples at different time points were carried out. The reason for the use of daily controls was to avoid ontogeny- and developmental-related variations in the metabolite and protein profiles. Those showing a minimum 2.0-fold change and significant differences in at least one of the time points ( $\alpha=0.05$; Student's $t$ test) are included in Table 1 . There was a good correlation between these metabolites and those highlighted in the HCL analysis. For instance, the nodule metabolite profile of plants experiencing mild drought showed moderate accumulations for carbohydrates such as fructose, galactinol, glucose, and sucrose together with the amino acids Trp, His, and Pro (Fig. 3A, column D3; Table 1, column D3/C3). There was also a remarkably high accumulation in the case of raffinose. Interestingly, the levels of $\alpha$-ketoglutaric and pyruvic acid were found to decline at this mild drought stage. In contrast, severe drought significantly altered the metabolic profiles of nodules (Fig. 3A, column D6; Table 1, column D6/C6), and those compounds that had started to accumulate under mild drought maintained this trend at D6. Carbohydrates such as trehalose and ribose; amino acids such as Asn, Ile, Leu, Phe, Ser, Thr, and Val; and the polyol myoinositol showed significant accumulations at D6. Nevertheless, this accumulation was not general, with the level of some compounds (including, for instance, the nonproteinogenic amino acid citrulline and dehydroascorbic acid) remaining almost unaltered, while others, such as the above-mentioned organic acids, continued decreasing. Rewatering reversed most of the drought-induced accumulation of compounds (Fig. 3A, column DR; Table 1, column DR/CR), with important exceptions. Some compounds which were highly accumulated during drought, such as Pro, His, and Trp, reduced their levels yet remained above control values. Rehydration also had specific effects on metabolites such as the sugar phosphates fructose-6$\mathrm{P}$ and glucose-6-P, whose levels, together with those of dehydroascorbic acid, were some of the most pronounced recoveryspecific declines observed.

For the identification of important variables and results interpretation with complex datasets, statistical tools such as principal and independent component analysis (PCA and ICA, respectively) are commonly used. PCA can be employed as a preprocessing step to reduce the complexity of the dataset and,
A

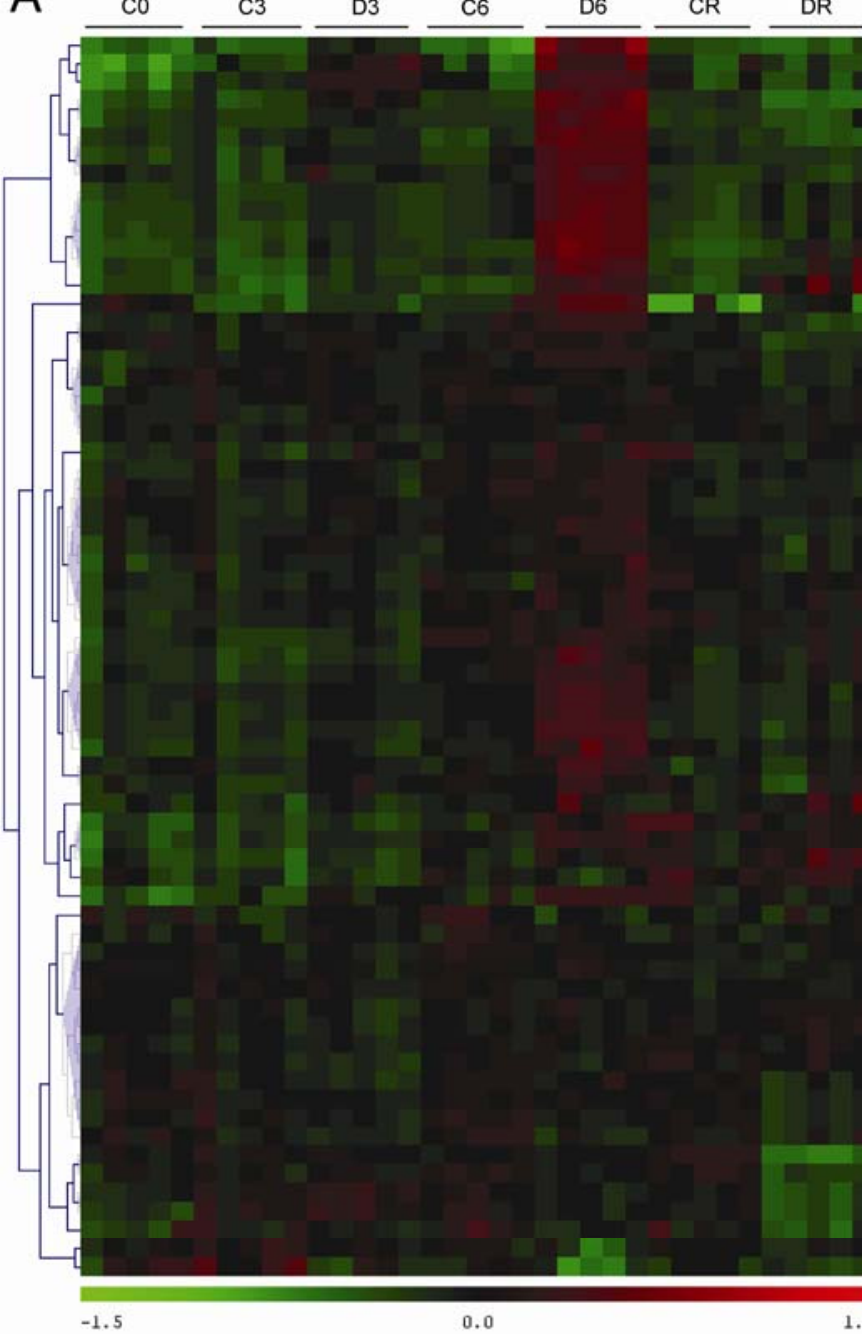

B

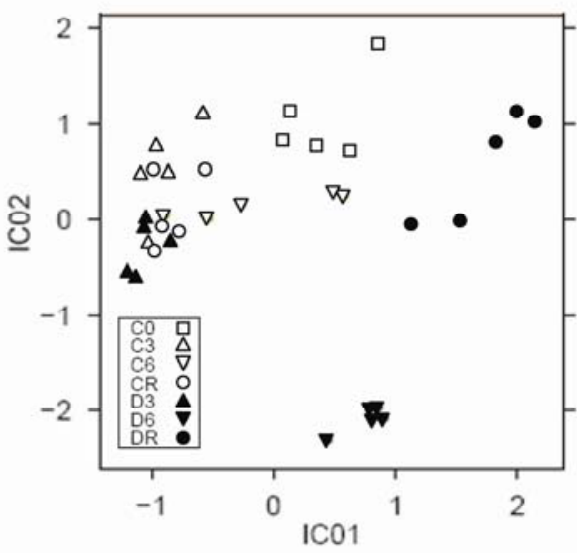

Fig. 3. Variations in the metabolite profiles of Medicago truncatula root nodules subjected to drought and recovery. A, Hierarchical clustering analysis (HCL) of the metabolite data. Based on their variations, metabolites fall into at least four categories: i) metabolites accumulated during drought, which returned to control values after recovery; ii) metabolites accumulated under drought and only partially returned to control levels upon rehydration; iii) metabolites at relatively constant values during the time course of the experiment, whose content declined in recovery samples; and iv) metabolites not showing significant changes during the experiment. B, Independent component analysis representation of the metabolic profiles of nodule samples. Each point summarises one complete metabolic profile. $\mathrm{C} 0$ represents samples at the beginning of the experiment; C3 and D3, control and drought on day 3; C6 and D6, control and drought on day 6; CR and DR, control and rehydrated plants. 
subsequently, ICA allows for the visualization of the data and the extraction of the most relevant proteins or metabolites, which are those showing the strongest influence on the separation of the samples (Daub et al. 2003; Scholz et al. 2004). In the present work, ICA was used to discriminate between the metabolic profiles of nodules from plants subjected to drought and recovery and those under control conditions (Fig. 3B). The dimension corresponding to IC2 can be considered as the component separating the effect of severe drought, because D6 samples clustered together and were distinctly separated from the rest of the samples. Metabolites presenting higher loading values based on this component were adenine, uracil, ribose, maleic acid, and Trp, all of them showing an accumulation at D6.

\section{Relative protein quantification in M. truncatula root nodules subjected to drought and recovery.}

The proteomic one dimensional (1D) liquid chromatography tandem mass spectrometry (LC-MS/MS) shotgun analysis allowed for the confident and simultaneous identification and quantification of 141 plant and 169 bacteroid proteins based on the spectral count method (Liu et al. 2004; Wienkoop et al. 2006). The complete protein lists, including both plant and bacteroid datasets, are provided as online supplemental material (Supplementary Tables S3 and S4 for M. truncatula and Sinorhizobium meliloti, respectively). The mass spectra resulting from the analysis were uploaded and stored in the mass spectral reference database PROMEX, where they can be publically accessed and searched for protein identification against unknown MS spectra (Hummel et al. 2007). The proteins identified here belong to the major plant and bacteroid metabolic pathways, including SNF, carbon metabolism, energy production, antioxidant defense, protein biosynthesis, and solute transport, in agreement with previous analysis of symbiotic root nodules at the protein (Natera et al. 2000; Bestel-Corre et al. 2002; Djordjevic et al. 2003; Catalano et al. 2004; Larrainzar et al. 2007) and transcript (El Yahyaoui et al. 2004) level. In addition, many of these proteins, especially those related to carbon metabolism, also have been identified in nonsymbiotic heterotrophic tissues of $M$. truncatula such as roots (Mathesius et al. 2001; Watson et al. 2003; Valot et al. 2004) and developing seeds (Gallardo et al. 2003).

Plant and bacteroid protein datasets were also subjected to data mining using ICA tools. The ICA plot for the plant protein analysis allowed for the distinct separation of D6 samples based on IC4, which could be considered as the component reflecting the effect of drought (Fig. 4A). The plant proteins with higher loading values in this component were Nod25 (TC106696), mitochondrial peroxiredoxin (TC107761), Cys proteinase inhibitor (TC101467), and histone H2A (TC96331), all of them detected only in D6 samples. It is interesting to note detection of a plant Cys proteinase inhibitor, which might be involved in counteracting an increased proteolysis activity induced by the drought treatment (Roy-Macauley et al. 1992; Degenkolbe et al. 2009). The ICA blot corresponding to the bacteroid proteomic analysis allowed for the discrimination between control and treated samples, including both drought

Table 1. Summary of the nodule metabolites identified in Medicago truncatula plants subjected to drought and subsequent rewatering ${ }^{\mathrm{a}}$

\begin{tabular}{|c|c|c|c|c|c|}
\hline Metabolite identification & $\mathbf{R T}^{\mathbf{b}}$ & $\mathbf{Q M}^{\mathbf{c}}$ & D3/C3 & D6/C6 & DR/CR \\
\hline \multicolumn{6}{|l|}{ Amino acids } \\
\hline Asparagine & 533.0 & 118 & $1.8 \pm 0.5$ & $3.3 \pm 0.2 * *$ & $1.1 \pm 0.1$ \\
\hline Citrulline & 584.8 & 157 & $1.1 \pm 0.1$ & $1.0 \pm 0.1$ & $2.6 \pm 0.6^{*}$ \\
\hline Histidine & 655.3 & 154 & $1.8 \pm 0.2 *$ & $4.1 \pm 0.3 * *$ & $1.5 \pm 1.0 *$ \\
\hline Isoleucine & 304.1 & 158 & $1.4 \pm 0.1$ & $5.2 \pm 0.3^{* *}$ & $1.6 \pm 0.3$ \\
\hline Leucine & 290.4 & 158 & $1.4 \pm 0.1$ & $4.0 \pm 0.2 * *$ & $1.4 \pm 0.2$ \\
\hline Phenylalanine & 511.0 & 192 & $1.1 \pm 0.1$ & $4.5 \pm 0.3 * *$ & $1.9 \pm 0.3 *$ \\
\hline Proline & 322.7 & 143 & $1.6 \pm 0.2 *$ & $6.6 \pm 0.6^{* *}$ & $3.0 \pm 0.7 *$ \\
\hline Serine & 341.4 & 204 & $1.1 \pm 0.1$ & $2.0 \pm 0.2 * *$ & $1.1 \pm 0.2$ \\
\hline Threonine & 351.5 & 219 & $1.3 \pm 0.1$ & $2.5 \pm 0.2 * *$ & $1.1 \pm 0.2$ \\
\hline Tryptophan & 765.6 & 202 & $2.2 \pm 0.2 *$ & $4.8 \pm 0.2 * *$ & $4.6 \pm 1.1 *$ \\
\hline Valine & 258.2 & 144 & $1.1 \pm 0.1$ & $2.4 \pm 0.1 * *$ & $1.0 \pm 0.1$ \\
\hline \multicolumn{6}{|l|}{ Carbohydrates } \\
\hline Fructose & 565.4 & 307 & $3.4 \pm 0.4^{* *}$ & $4.7 \pm 0.9 * *$ & $0.9 \pm 0.2$ \\
\hline Fructose-6-phosphate & 743.2 & 315 & $1.2 \pm 0.1$ & $0.7 \pm 0.1$ & $0.4 \pm 0.1 * *$ \\
\hline Galactinol dihydrate & 914.3 & 204 & $2.4 \pm 0.2 * *$ & $6.3 \pm 0.7 * *$ & $0.4 \pm 0.1 * *$ \\
\hline Glucose & 571.0 & 319 & $2.3 \pm 0.3 *$ & $2.8 \pm 0.1 * *$ & $0.7 \pm 0.1$ \\
\hline Glucose-6-phosphate & 749.6 & 387 & $1.2 \pm 0.1$ & $0.7 \pm 0.1 *$ & $0.4 \pm 0.1 * *$ \\
\hline Maltose & 847.0 & 271 & $1.5 \pm 0.1 *$ & $1.5 \pm 0.3$ & $0.7 \pm 0.1$ \\
\hline Raffinose & 1007.3 & 361 & $2.0 \pm 0.1 * *$ & $21.5 \pm 4.5^{* *}$ & $0.8 \pm 0.1$ \\
\hline Ribose & 482.8 & 307 & $1.0 \pm 0.1$ & $2.2 \pm 0.3^{*}$ & $0.6 \pm 0.1$ \\
\hline Sucrose & 816.8 & 362 & $2.2 \pm 0.1 * *$ & $2.9 \pm 0.1 * *$ & $0.6 \pm 0.1$ \\
\hline Trehalose & 851.7 & 361 & $1.3 \pm 0.1$ & $5.7 \pm 0.5^{* *}$ & $0.6 \pm 0.1$ \\
\hline \multicolumn{6}{|l|}{ Organic acids } \\
\hline$\alpha$-Ketoglutaric acid & 503.7 & 198 & $0.3 \pm 0.1 *$ & $0.2 \pm 0.1^{*}$ & $0.7 \pm 0.1$ \\
\hline Dehydroascorbic acid & 603.7 & 173 & $0.9 \pm 0.1$ & $0.9 \pm 0.1$ & $0.2 \pm 0.1 * *$ \\
\hline Glyceric acid & 328.9 & 189 & $1.3 \pm 0.2$ & $2.2 \pm 0.1 * *$ & $0.9 \pm 0.1$ \\
\hline Maleic acid & 356.4 & 133 & $1.6 \pm 0.2 *$ & $4.2 \pm 0.4 * *$ & $5.9 \pm 0.6^{* *}$ \\
\hline Pyruvic acid & 210.7 & 174 & $0.7 \pm 0.1 *$ & $0.4 \pm 0.2$ & $0.8 \pm 0.1$ \\
\hline \multicolumn{6}{|l|}{ Polyols } \\
\hline Myo-inositol & 633.6 & 434 & $1.1 \pm 0.1$ & $6.0 \pm 0.2 * *$ & $0.6 \pm 0.1 * *$ \\
\hline \multicolumn{6}{|l|}{ Others } \\
\hline Adenosine & 895.0 & 236 & $1.0 \pm 0.1$ & $0.7 \pm 0.1 *$ & $0.4 \pm 0.1 * *$ \\
\hline 5'-Adenylic acid & $1,027.2$ & 169 & $0.7 \pm 0.1$ & $0.6 \pm 0.1^{*}$ & $0.4 \pm 0.1 *$ \\
\hline
\end{tabular}

${ }^{a}$ Metabolites were relatively quantified using sorbitol as internal standard, and values are given on a dry-weight basis. Variations of the levels of metabolites are presented as ratios calculated by dividing the amount of a certain compound present in mild drought (D3), severe drought (D6), and recovery (DR) samples and their respective control plants. Metabolites that showed a minimum 2.0-fold change and significant variations in at least one of the conditions assayed (marked with * for $\alpha=0.05$ and ** for $\alpha=0.01$; Student's $t$-test) are presented. Results are given as average \pm standard error of five biological replicates.

${ }^{\mathrm{b}}$ Retention time.

c Masses used for quantification. 
and recovery treatments, based on IC2 (Fig. 4B). The following proteins were most influential in the separation of the samples: a transcription regulator cold-shock-like protein (Smc04234), which was only detected in recovery samples; a DNA-directed RNA polymerase (Smc01317), which was not detected in severe drought and recovery samples; and a phosphoserine aminotransferase (Smc00640), only identified in control plants. Apart from the effect of drought, a timedependent variation in the protein profiles was observed. For instance, in the ICA blots corresponding to the bacteroid protein analysis (Fig. 4B), with the exception of the recovery protein samples, it appears that IC1 identifies a time-dependent variation in the protein profiles, because day 0 and 3 samples are in the negative value range while day 6 and control recovery samples are in the positive range. These variations might be attributable to development processes taking place in nodules during the duration of the experiment.
Further detailed analysis of results was carried out and protein data were processed in a way similar to metabolite data. Plant and bacteroid proteins showing a minimum 2.0-fold change in the DR/CR to D6/C6 ratio and significant variations ( $\alpha=0.05$; Student's $t$ test) in at least one of the conditions assayed are summarized in Tables 2 and 3, respectively.

Besides confirming previous results (Larrainzar et al. 2007), the relative plant protein analysis showed that severe drought induced a decline in the content of proteins such as a 14-3-3like protein (TC106310), cytosolic malate dehydrogenase (TC100429), and enolase (TC100309). In contrast, enzymes related to $\mathrm{C}$ metabolism such as fructokinase (TC94345), triosephosphate isomerase (TC93925), and fructose-bisphosphate aldolase (TC106580) were found to accumulate upon rewatering.

Regarding the $S$. meliloti protein analysis, the present work showed a reduction in the level of a number of bacteroid pro-
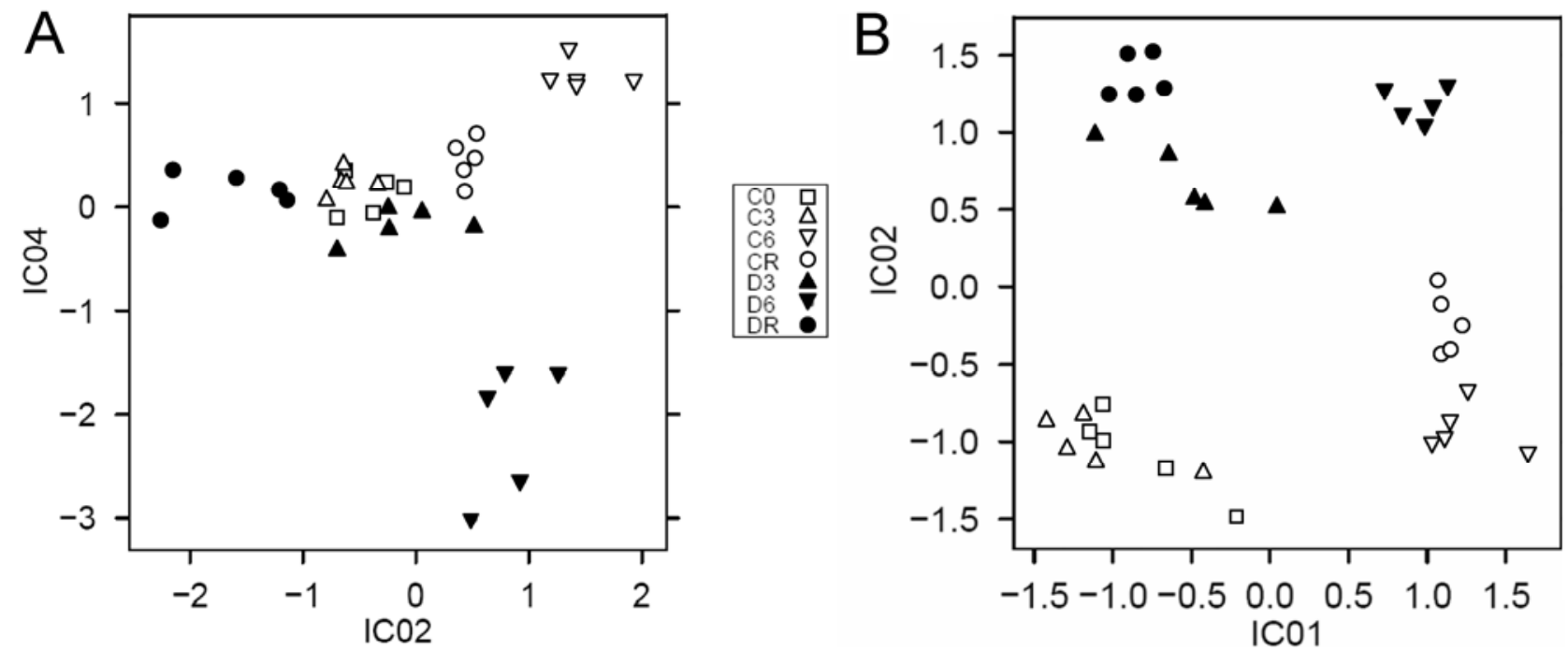

Fig. 4. Independent component analysis plots of $\mathbf{A}$, plant and $\mathbf{B}$, bacteroid proteomic analysis during drought and recovery for sample pattern recognition in Medicago truncatula root nodules. C0 represents nodule samples at the beginning of the experiment; C3 and D3, control and drought on day 3; C6 and D6, control and drought on day 6; CR and DR, control and rehydrated plants. Each point in the graph summarises the whole protein profile of one biological replicate $(n=5)$.

Table 2. Summary of the plant nodule proteins identified in Medicago truncatula plants subjected to drought and subsequent rewatering ${ }^{\mathrm{a}}$

\begin{tabular}{llllll}
\hline ID & D3/C3 & D6/C6 & DR/CR & $\begin{array}{c}\text { (DR/CR)/ } \\
\text { (D6/C6) }\end{array}$ & \multicolumn{1}{c}{ Protein description } \\
\hline TC106593 & $1.2 \pm 0.1$ & $0.6 \pm 0.1^{*}$ & $2.4 \pm 0.2^{* *}$ & 4.0 & Similar to UP|Q42928 Leghemoglobin \\
TC106598 & $1.4 \pm 0.3$ & $0.6 \pm 0.1^{*}$ & $2.3 \pm 0.2^{* *}$ & 3.8 & Homologue to UP|Q71EW8 Met synthase \\
TC94345 & $0.6 \pm 0.1$ & $0.6 \pm 0.1$ & $2.2 \pm 0.2^{* *}$ & 3.5 & Similar to UP|Q42645 Fructokinase \\
TC100410 & $0.8 \pm 0.1$ & $0.6 \pm 0.1^{*}$ & $1.8 \pm 0.3$ & 3.2 & UP|Q9T0M6 SuSy1 \\
TC106310 & $0.7 \pm 0.1^{*}$ & $0.6 \pm 0.1^{* *}$ & $1.5 \pm 0.2$ & 2.5 & Homologue to UP|Q9XG89 14-3-3-like protein \\
TC93925 & $1.1 \pm 0.1$ & $0.9 \pm 0.2^{*}$ & $2.3 \pm 0.2^{* *}$ & 2.4 & Homologue to UP|Q6GW08 Triosephosphate isomerase \\
TC100429 & $0.9 \pm 0.1$ & $0.7 \pm 0.1^{* *}$ & $1.6 \pm 0.1^{* *}$ & 2.4 & UP|O48905 Malate dehydrogenase \\
TC93936 & $1.0 \pm 0.2$ & $0.6 \pm 0.1^{*}$ & $1.4 \pm 0.4^{*}$ & 2.3 & Homologue to UP|Q9ASR1 Elongation factor 2 \\
TC100309 & $0.8 \pm 0.1^{*}$ & $0.6 \pm 0.1^{*}$ & $1.3 \pm 0.1^{*}$ & 2.3 & Homologue to UP|Q6RIB7 Enolase \\
TC106580 & $1.2 \pm 0.2$ & $0.8 \pm 0.1$ & $1.7 \pm 0.1^{* *}$ & 2.2 & Homologue to UP|P46257 Fructose-bisphosphate aldolase 2 \\
TC94002 & $1.1 \pm 0.1$ & $0.7 \pm 0.1^{*}$ & $1.6 \pm 0.4$ & 2.1 & Homologue to UP|Q9LKJ2 Phosphoglycerate kinase \\
TC107133 & $0.9 \pm 0.2$ & $0.9 \pm 0.1$ & $0.4 \pm 0.1^{* *}$ & 0.5 & Homologue to UP|Q08480 Adenylate kinase B \\
TC106384 & $0.6 \pm 0.1^{*}$ & $1.1 \pm 0.1$ & $0.6 \pm 0.1^{* *}$ & 0.5 & Homologue to UP|Q9AT55 S-adenosyl-L-Met synthetase \\
TC106311 & $2.1 \pm 0.3^{* *}$ & $0.9 \pm 0.1$ & $0.4 \pm 0.1^{*}$ & 0.4 & Similar to UP|Q41119 Cyclophilin \\
TC93931 & $1.0 \pm 0.2$ & $1.0 \pm 0.1$ & $0.4 \pm 0.1^{* *}$ & 0.4 & Homologue to UP|Q9SBR9 Basic blue protein \\
TC100674 & $1.4 \pm 0.3$ & $1.5 \pm 0.2^{*}$ & $0.5 \pm 0.1^{* *}$ & 0.3 & Similar to S48643 ATP synthase \\
\hline
\end{tabular}

${ }^{a}$ Proteins were relatively quantified using the spectral count method (Liu et al. 2004; Wienkoop and Weckwerth 2006). Variations of the protein levels are given as ratios calculated by dividing the number of spectral counts of a certain protein present in mild drought (D3), severe drought (D6), and recovery (DR) samples and their respective control plants. Proteins which showed a minimum 2.0-fold change in the DR/CR to D6/C6 ratio and significant variations in at least one of the conditions assayed (marked with * for $\alpha=0.05$ and $* *$ for $\alpha=0.01$; Student's $t$-test) are presented. Values are represented as average \pm standard error of five biological replicates.

${ }^{\mathrm{b}}$ Identification code of tentative consensus (TC) sequences as retrieved from the Dana Farber Cancer Institute (DFCI) M. truncatula Gene Index release 8.0 database. 
teins involved in SNF, including components of the nitrogenase complex NifD, NifH, and NifK (SMa0827, SMa0825, and SMa0829), and proteins FixA and FixC (SMa0822 and SMa0817). In particular, NifH, FixC, and a transmembrane dihydrolipoamide dehydrogenase (LpdA) significantly declined at the early drought stage, D3. Upon rewatering, the abovementioned SNF proteins, along with proteins related to $\mathrm{C}$ metabolism, including malate dehydrogenase (SMc0279) and citrate synthase (SMc02087), showed an accumulation which correlates well with the observed improvement of SNF rates measured in planta (Fig. 1B). However, others, such as an iron binding protein (SMc00784) and FixU (SMa0810), were found to be less abundant in recovery samples.

\section{Absolute protein quantification of SuSy and $\mathrm{N}$ assimilation enzymes in $M$. truncatula root nodules subjected to drought and recovery.}

In order to analyze in detail the possible involvement of $\mathrm{N}$ assimilation on the regulation of SNF in M. truncatula, variations in the protein content of the main enzymes involved in this pathway were monitored during drought and recovery using absolute quantification techniques, as previously described (Wienkoop et al. 2008). Particularly, the levels of Asn synthetase (AS), Gln synthetase (GS), Glu dehydrogenase (GDH), and Asp aminotransferase (AAT) were successfully determined at the isoform level. Although transcriptomic studies have already shown the expression profile of $\mathrm{N}$ assimilation enzymes in developing nodules (El Yahyaoui et al. 2004), these enzymes are rarely detected in nodule proteomic studies (Bestel-Corre et al. 2002; Natera et al. 2000), which highlights the importance of the analysis of the complete pathway presented here (Fig. 5). Furthermore, given its essential role in the regulation of SNF via $\mathrm{C}$ metabolism, the nodule-enhanced SuSy isoform (SuSy1) was also subjected to absolute quantification (Fig. 5).

In $M$. truncatula nodules, at least three GS isoforms are reported to be expressed: GS1a, GS1b, and GS2 (Carvalho et al. 2000). Out of the two cytosolic isoenzymes (GS1a and b, corresponding to TC106729 and TC106808 in the Medicago Gene Index 8.0, respectively), only the most abundant one (GS1a, with average control levels of $94 \pm 8 \mathrm{pmol} / \mathrm{mg}$ of total protein) experienced a slight decrease on D6; a trend which was not reversed by rehydration. The levels of GS2 (TC106913), the plastid-localized isoform, were also lower in drought-recovered samples when compared with control plants. GS and NADHdependent glutamate synthase (NADH-GOGAT) are considered to be the main enzymes involved in the assimilation of symbiotically-fixed $\mathrm{N}$ in nodules (Groat and Vance 1981); therefore, attempts to monitor nodule NADH-GOGAT (TC94780) were made. However, the levels of this enzyme appeared to be below the detection limits of the technique under the conditions tested. In contrast, it was possible to monitor the effects of drought and recovery on the other ammonium assimilating enzyme in nodules, GDH (TC94704). Despite being close to the detection limit and, thus, exhibiting high variance, GDH appeared to decline in recovery samples. Regarding AAT, three isoforms were analyzed: the first two, AAT1 (TC106918) and AAT2 (TC94631), were identified based on their homology to M. sativa AAT proteins (Shi et al. 1997), while the third isoform (here named AAT3; TC94623), is described here for the first time in M. truncatula, based on the homology shown with an AAT found in Oryza sativa and Arabidopsis thaliana. Based on transcript analysis, AAT2 is considered to be the nodule-enhanced isoform, a hypothesis which was corroborated here at the protein level. AAT1 and the newly identified AAT3 were found to be less abundant but still detectable. The drought treatment did not equally affect all of them: while the levels of AAT2 and AAT3 were slightly reduced under D3, AAT1 levels did not experience significant changes. With regard to $\mathrm{AS}$, the two isoforms quantified (TC100391 and TC100393) were present at similar levels (approximately $70 \mathrm{pmol} / \mathrm{mg}$ of total protein) and responded similarly, declining under drought and not recovering upon rehydration.

In contrast, the content of SuSy1 showed a partial decline at D3, which was more dramatic at D6, dropping from $115 \pm 5$ to $16 \pm 2 \mathrm{pmol} / \mathrm{mg}$ of total protein, a decline that was partially reversed by rewatering. These variations were found to mirror those of SNF measured as ANA (Fig. 1) and are in agreement with the trend observed for SuSy1 in the relative quantification analysis (Table 2).

\section{DISCUSSION}

\section{Drought induces a decline in $\mathrm{C}$ metabolism and nitrogenase activity, but $\mathrm{N}$ assimilation enzymes are largely unaffected.}

Elevated levels of nitrogenous compounds, including ureides and amino acids, have been proposed to play a role in the decline of SNF in legumes in response to water-deficit stress. For instance, the accumulation of free amino acids has been implicated in the feedback inhibition of SNF in response to polyethyl-

Table 3. Summary of the bacteroid nodule proteins identified in Medicago truncatula plants subjected to drought and subsequent rewatering ${ }^{\mathrm{a}}$

\begin{tabular}{|c|c|c|c|c|c|}
\hline ID $^{\mathbf{b}}$ & D3/C3 & D6/C6 & DR/CR & (DR/CR)/(D6/C6) & Protein description \\
\hline SMa0829 & $0.8 \pm 0.1$ & $0.6 \pm 0.1 * *$ & $2.3 \pm 0.2 * *$ & 3.8 & NifK nitrogenase Fe-Mo $\beta$ chain \\
\hline SMc04405 & $0.8 \pm 0.2$ & $0.8 \pm 0.1$ & $3.0 \pm 0.3 * *$ & 3.8 & 3-Isopropylmalate dehydrogenase B \\
\hline SMa0817 & $0.5 \pm 0.1 * *$ & $0.6 \pm 0.1 * *$ & $2.0 \pm 0.2 * *$ & 3.6 & FixC oxidoreductase \\
\hline $\mathrm{SMa} 0822$ & $0.8 \pm 0.1$ & $0.6 \pm 0.1 *$ & $2.1 \pm 0.4 *$ & 3.4 & FixA electron transfer flavoprotein $\beta$ chain \\
\hline $\mathrm{SMa} 0827$ & $0.9 \pm 0.1$ & $0.6 \pm 0.1 *$ & $1.8 \pm 0.2 * *$ & 2.9 & NifD nitrogenase Fe-Mo $\alpha$ chain \\
\hline SMc02479 & $0.7 \pm 0.1$ & $0.6 \pm 0.1^{*}$ & $1.7 \pm 0.1 * *$ & 2.7 & Malate dehydrogenase \\
\hline SMc03846 & $0.9 \pm 0.1$ & $0.8 \pm 0.1$ & $1.6 \pm 0.1 * *$ & 2.6 & Aconitate hydratase \\
\hline SMc01031 & $0.8 \pm 0.1$ & $0.6 \pm 0.1 * *$ & $1.6 \pm 0.1 * *$ & 2.6 & Pyruvate dehydrogenase $\beta 2$ subunit \\
\hline SMc02487 & $0.4 \pm 0.1 *$ & $0.6 \pm 0.1 *$ & $1.5 \pm 0.1 *$ & 2.4 & Transmembrane dihydrolipoamide dehydrogenase \\
\hline SMa0825 & $0.8 \pm 0.1 *$ & $0.7 \pm 0.1 *$ & $1.5 \pm 0.1 * *$ & 2.2 & NifH nitrogenase Fe protein \\
\hline SMc00784 & $1.0 \pm 0.1$ & $1.0 \pm 0.1$ & $0.5 \pm 0.1 * *$ & 0.5 & Iron-binding protein \\
\hline SMc02481 & $1.6 \pm 0.1 *$ & $1.0 \pm 0.1$ & $0.5 \pm 0.1 *$ & 0.5 & Succinyl-CoA synthetase $\alpha$ chain \\
\hline $\mathrm{SMa} 0810$ & $1.3 \pm 0.2$ & $1.1 \pm 0.1$ & $0.5 \pm 0.1 * *$ & 0.4 & FixU nitrogen fixation protein \\
\hline SMc00595 & $0.5 \pm 0.2$ & $1.0 \pm 0.1$ & $0.5 \pm 0.2 *$ & 0.4 & Nucleoside diphosphate kinase \\
\hline
\end{tabular}

${ }^{a}$ Proteins were relatively quantified using the spectral count method (Liu et al. 2004; Wienkoop and Weckwerth 2006). Variations of the protein levels are given as ratios calculated by dividing the number of spectral counts of a certain protein present in mild drought (D3), severe drought (D6), and recovery (DR) samples and their respective control plants. Proteins which showed a minimum 2.0-fold change in the DR/CR to D6/C6 ratio and significant variations in at least one of the conditions assayed (marked with * for $\alpha=0.05$ and ** for $\alpha=0.01$; Student's $t$-test) are presented. Values are represented as average \pm standard error of five biological replicates.

${ }^{\mathrm{b}}$ Identification code of the corresponding gene as retrieved from the Sinorhizobium meliloti 1021 Genome Database. 
ene glycol-induced water deficits in alfalfa (Schubert et al. 1995) and soybean (Serraj et al. 1998). King and Purcell (2005), attempting to identify the nitrogenous compounds whose increase and decrease in concentration mirrored the droughtinduced decline of SNF, suggested that nodule ureides and Asp, together with several amino acids in leaves, could be potential candidate molecules for feedback inhibition of SNF in soybean. Following this approximation and assuming that, in $M$. truncatula, SNF is regulated at the local and not systemic level, as shown for pea and soybean (Ladrera et al. 2007; Marino et al. 2007), an $\mathrm{N}$ feedback regulation mechanism operating in the model legume would imply the existence of a nitrogenous compound in nodules, which mirrored the variations of SNF. Apart from the strong accumulation of Pro, a classical drought stress marker, the only significant amino acid variations detected at the early stages of drought (D3), when ANA has already dropped $30 \%$, are those of His and Trp. This is a novel finding, considering that more abundant amino acids, such as Asn, Asp, Gln, or Glu, are frequently suggested to be involved in SNF inhibition (Bacanamwo and Harper 1997; Neo and Layzell 1997; Vadez et al. 2000).

In addition to searching for possible $\mathrm{N}$ regulatory compounds in nodules, the effect of drought on the $\mathrm{N}$ assimilation pathway was analyzed via absolute quantification, a method that offers a number of advantages when compared with immunodetection analysis, including the possibility to specifically target different protein isoforms (Lehmann et al. 2008; Wienkoop et al. 2008). Information gathered from this analysis showed that $\mathrm{N}$ assimilation is largely unaffected in the initial stages of drought. Only the two most abundant AAT isoforms, AAT2 and the newly identified AAT3, showed a decrease at D3. In the later drought stage (D6), GS1a, the most abundant GS isoform in $M$. truncatula nodules, and AS2 also showed a modest decline. This suggests that only at D6, where SNF is severely impaired $(-76 \%)$, do $\mathrm{N}$ assimilation and Asn synthesis start to be downregulated. Interestingly, it is after rewatering when most of the enzymes involved in $\mathrm{N}$ assimilation experience a decrease. Altogether, nodule $\mathrm{N}$ assimilation is found not to correlate with the decline in SNF in drought-stressed M. truncatula plants. However, our results do not exclude a possible regulation of these proteins at the post-translational level. Indeed, evidence for GS phosphorylation in $M$. truncatula nodules has recently been provided (Lima et al. 2006), although the physiological implications of these post-translational modifications remain unknown. The lack of correlation between SNF and N assimilation during the early stages of drought found in the present work is consistent with previous studies on other legume species. For instance, GS transcription, protein levels, and enzymatic activity have been found

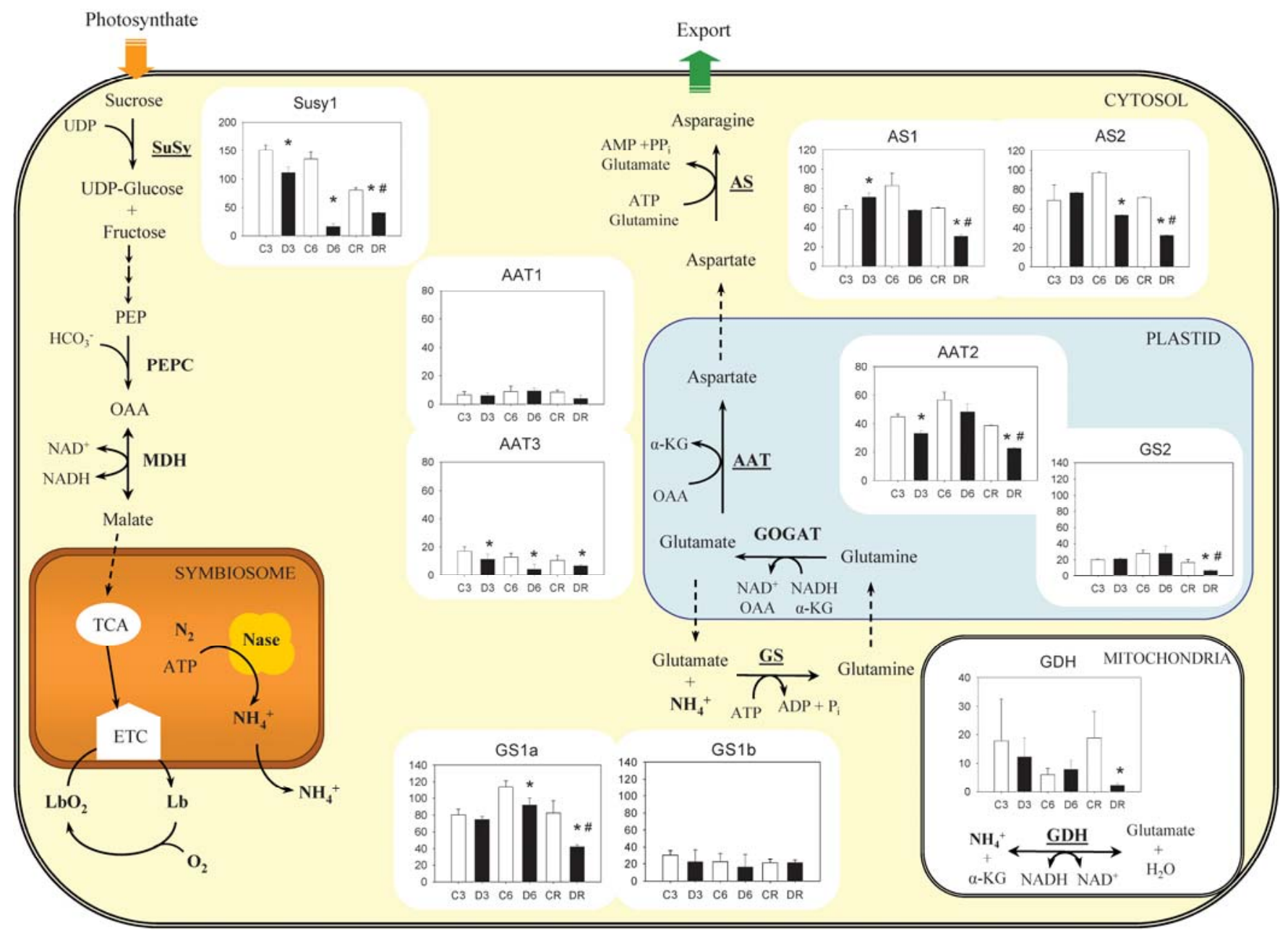

Fig. 5. Absolute quantification of enzymes involved in $\mathrm{C}$ and $\mathrm{N}$ metabolism in Medicago truncatula root nodules during drought and recovery. Protein isoforms for which subcellular localization has been reported in legumes are located in the diagram accordingly. Absolute values are expressed as pmoles of a specific protein per milligrams of total nodule protein. Values represented are the average of five biological replicates and error bars correspond to the standard deviation of the samples. C3, control day 3; D3, drought day 3; C6, control day 6; D6, drought day 6; CR, control recovery; DR, drought recovery; $\alpha$-KG, $\alpha$-ketoglutarate; OAA, oxaloacetate; PEP(C), phosphoenolpyruvate (carboxilase); GS, Gln synthetase; AAT, Asp aminotransferase; AS, Asn synthetase; GDH, Glu dehydrogenase; MDH, malate dehydrogenase; SuSy, Suc synthase. Significant differences between treated and control samples at $\alpha=0.05$ (Student's $t$ test) are marked with an asterisk (*). Significant differences between DR and D6 samples are indicated with a hash (\#). 
not to consistently change in response to drought stress (González et al. 1995; Gordon et al. 1997; Ramos et al. 1999).

SuSy is a key enzyme in the metabolization of sucrose in sink tissues such as mature $\mathrm{N}_{2}$-fixing nodules (Anthon and Emerich 1990; Gordon et al. 1999). Mutations producing reduced SuSy activity levels in nodules lead to deficient SNF capacity, as initially shown for pea (Craig et al. 1999) and, more recently, for Lotus japonicus (Horst et al. 2007) and M. truncatula (Baier et al. 2007). In legumes such as pea and soybean, drought induces a reduction in the levels of nodule SuSy (González et al. 1995, 1998), leading to a limitation of respiratory substrate for bacteroids in the form of malate (Gálvez et al. 2005; Ladrera et al. 2007). However, recent studies in $M$. sativa observed a decline in SNF precedent to a decline in SuSy and the accumulation of malate, suggesting that $\mathrm{C}$ limitation was not the cause of the drought-induced loss of nitrogenase activity in alfalfa nodules (Naya et al. 2007). In a previous proteomic work, based on relative quantification analysis, SuSy1, the nodule-enhanced isoform (Hohnjec et al. 2003), was among the plant proteins most affected by drought in $M$. truncatula nodules (Larrainzar et al. 2007), but its possible role in the regulation of SNF was not specifically addressed. In the present study, we applied absolute quantification techniques to monitor the levels of SuSy1, which allowed us to detect a decline in its content by D3 (-26\%). This decline, although moderate, may account for the observed accumulation of sucrose in nodules by D3. However, malate did not show significant variations during drought. This result was further validated using targeted analysis of organic acids in nodules, which showed that malate content did not decrease in drought-stressed nodules, in contrast to observations in pea and soybean, but maintained levels close to control values (D6 and C6 nodule samples contained $61.9 \pm 0.8$ and $55.8 \pm 1.3 \mu \mathrm{mol} / \mathrm{g}$ of nodule dry weight, respectively). This suggests that, despite the availability of malate, it is not metabolized by the bacteroids in drought-stressed nodules.

Evidence for an impairment of bacteroid metabolism also comes from the bacteroid proteomic analysis, which showed the early decline of a number of proteins by D3, namely $\mathrm{NifH}$, FixC, and a transmembrane dihydrolipoamide dehydrogenase (LpdA). This decline was more pronounced in the more severe drought stage and the trend was reversed by rewatering. Although NifH is a well-known protein, corresponding to the Fe protein subunit of the nitrogenase complex, little is known about the latter proteins. FixC has been described as a flavoprotein ubiquinone oxidoreductase, suggested to be involved in electron transfer to the nitrogenase complex (Edgren and Nordlund 2004; Sperotto et al. 2004). The combined effect of reductions in both $\mathrm{NifH}$ and FixC is likely to be diminished nitrogenase functioning, leading to a reduction in SNF and the observed lower demand for malate consumption. On the other hand, LpdA is a functional subunit of the pyruvate dehydrogenase complex, involved in the oxidation of pyruvate to acetyl-CoA. Interestingly, the decline of LpdA correlates well with the fact that the levels of pyruvate are reduced at D3, along with a partial reduction in the levels of pyruvate dehydrogenase at this drought stage. Taken together, these results suggest that, although the decline in SuSy1 content occurs in parallel to the decrease of SNF, a limitation of $\mathrm{C}$ respiratory substrate for nitrogenase is not the cause of the inhibition of SNF in M. truncatula under drought. Rather, it is due to an impairment of bacteroid metabolism and $\mathrm{N}_{2}$-fixing capacity.

\section{Reactivation of nodule functioning during recovery involves increased levels of proteins related to plant and bacteroid $\mathrm{C}$ metabolism and SNF.}

Under field conditions, plants are generally exposed to repeated short- or long-term soil drought stress, and plant sur- vival and crop productivity depends not only on the protection mechanisms which prevent cellular damage during the stress but also on the capability to reestablish normal functioning (Torres-Franklin et al. 2007). Despite its importance, the metabolic processes occurring after rehydration are poorly known and few studies have focused on the recovery of SNF in legumes (Fellows et al. 1987; Davey and Simpson 1990; Venkateswarlu et al. 1990; King and Purcell 2005; Naya et al. 2007). The present work is, to our knowledge, the first study that combines proteomic and metabolomic analysis for the study of an abiotic stress such as drought and its subsequent recovery in legumes nodules.

Based on the metabolic changes observed, drought-stressed nodules experience an accumulation of sugars (mostly sucrose, fructose, glucose, and raffinose), polyols (myo-inositol and pinitol), and amino acids (Pro, Trp, and His during early drought followed by Asn, Ile, Leu, Val, Thr, and Ser at a later stage). Why do these compounds accumulate during drought? There are several, not mutually exclusive, possibilities: i) some of these compounds (i.e., raffinose, which has been proposed to be involved in reactive oxygen species scavenging [Van den Ende and Valluru 2009], or polyols) are described as compatible osmolytes that could be playing a role in osmotic regulation processes in nodules (Streeter 1987; Fougere et al. 1991; Muller et al. 1996); ii) alterations in cellular metabolism may occur, which would lead, for example, to impairment of nodule respiration or disturbances in protein synthesis or degradation or both; or iii) the accumulation of these compounds could be related to the reduction of plant transpiration rates during drought, which would limit the xylematic flux and, consequently, the export of compounds from nodules. However, if a reduction of water-based export from the nodules were the main reason for the metabolic changes observed, this would imply a general accumulation of metabolites during drought, which does not explain the specific accumulation of compounds found in this study.

Plant rewatering was able to reverse these accumulation trends, leading to an increase in many of the proteins negatively affected by drought. Notable among these were those related to the process of SNF, including a leghemoglobin isoform and a number of bacteroid proteins such as NifD, NifK, and NifH and FixA and FixC. Additionally, the droughtinduced downregulation of $\mathrm{C}$ metabolism was reversed upon rewatering in both the plant and bacteroid components, with an increase in the content of plant SuSy (measured at both the absolute and relative levels), malate dehydrogenase, fructokinase, triosephosphate isomerase, and fructose-bisphosphate aldolase, along with the bacteroid isopropylmalate dehydrogenase, aconitase hydratase, LpdA, and pyruvate dehydrogenase. These observations point in the direction of a reactivation of nodule metabolism in two interconnected key aspects: $\mathrm{C}$ metabolism and SNF. In contrast, based on the absolute quantification results, nodule $\mathrm{N}$ assimilation processes do not show this co-regulation with SNF during recovery, with most of the enzymes showing a decline in their content. This further suggests that $\mathrm{C}$ and $\mathrm{N}$ assimilation are differentially regulated during drought and recovery, the former mirroring the evolution of SNF and cellular energy status while the latter may be involved in other metabolic process, such as restoring the amino acid balance in nodules. This differential response in the recovery from drought stress is further corroborated at the metabolite level, with most of the carbohydrates recuperating control values after rewatering, while certain amino acids, interestingly those showing an early accumulation (Pro, His, and Trp), remained above control levels.

Furthermore, recovery induced specific variations in the content of a number of metabolites and proteins. This is the 
case for the dehydroascorbic acid and the plant enzyme adenylate kinase, which is related to cellular energy metabolism (Pradet and Raymond 1983), along with bacteroid FixU and an iron-binding protein, all of which were largely unaffected by drought but decreased upon rewatering, suggesting a specific involvement during recovery.

\section{Conclusions.}

The amino acids His and Trp were found to significantly accumulate at the early stages of drought in M. truncatula nodules, mirroring the decline in ANA, a correlation which could not be made for other predominant $\mathrm{N}$ compounds previously suggested to be involved in the inhibition of SNF. Absolute quantification results demonstrated that the variations in the levels of nodule $\mathrm{N}$ assimilation enzymes were not correlated with those of ANA, which does not support a role for $\mathrm{N}$ assimilation in the regulation of SNF during drought but, rather, in the reestablishment of an amino acid balance during recovery. Regarding C metabolism, inhibition of SNF in M. truncatula under drought stress appears to be related to an impairment of bacteroid metabolism and $\mathrm{N}_{2}$-fixing capacity rather than to a limitation of $\mathrm{C}$ respiratory substrate to fuel bacteroid nitrogenase; in contrast to the model proposed for other legumes such as pea and soybean (González et al. 1995, 1998; Gálvez et al. 2005; Ladrera et al. 2007). In this sense, the regulation of SNF in $M$. truncatula during drought shows more similarities with other species such as M. sativa (Naya et al. 2007), suggesting a possible common regulatory response among pasture legumes. In these plants, the microsymbiont rather than the host plant appears to play a crucial role in the inhibition of SNF under stress conditions. Furthermore, our results highlight the importance of the reactivation of plant and bacteroid $\mathrm{C}$ metabolism, along with the recuperation of SNF capacity, suggesting the involvement of novel proteins in the recovery process.

\section{MATERIALS AND METHODS}

\section{Biological material, growth conditions, and drought and recovery treatment.}

M. truncatula 'Jemalong A17' plants inoculated with $S$. meliloti strain 2011 were grown in 1-liter pots with a mixture of vermiculite/perlite $(5: 2, \mathrm{vol} / \mathrm{vol})$ as substrate under controlled environmental conditions (14-h day and 10-h night; $600 \mu \mathrm{mol} \mathrm{m} \mathrm{m}^{-2} \mathrm{~s}^{-1}$ light intensity; 22 and $16^{\circ} \mathrm{C}$ day and night temperatures, respectively; 70 to $60 \%$ relative humidity). Plants were watered with nutrient solution (Evans 1981) containing $0.25 \mathrm{mM}$ ammonium nitrate for the first 4 weeks in order to improve plant performance during the initial development stage. During the following weeks, nutrient solution was $\mathrm{N}$ free. When plants were 10 weeks old, they were randomly separated into two sets: control and drought-stressed. Control plants were supplied daily with nutrient solution to field capacity whereas drought stress was imposed on the other group by withholding water and nutrients for either 3 or 6 days. Recuperation was carried out by rewatering drought-stressed plants for 2 days. Both treated and control plants were harvested at set time points: day 0 , day 3, day 6 , and day 8. ANA was estimated by $\mathrm{H}_{2}$-evolution from intact plants in an open flow-through system under $\mathrm{N}_{2}: \mathrm{O}_{2}(79: 21 \%$, vol/vol), according to Witty and Minchin (1998), using an electrochemical $\mathrm{H}_{2}$ sensor (Qubit System Inc., Ontario, Canada). Nodule water potential $\left(\psi_{\mathrm{w}}\right)$ was measured in C52 sample chambers connected to a Wescor HR-33T dew point hygrometer (Wescor, Logan, UT, U.S.A.). Root nodules were collected, frozen in liquid nitrogen, and stored at $-80^{\circ} \mathrm{C}$ for further analysis.
Integrative protein and metabolite extraction.

The integrative extraction of metabolites and proteins was carried out as previously described (Morgenthal et al. 2007). For each treatment, nodules from five biological replicates were analyzed. Frozen nodule samples (approximately $0.1 \mathrm{~g}$ fresh weight) were ground under liquid nitrogen using a Retsch ball mill grinder, and $4 \mathrm{ml}$ of ice-cold methanol/chloroform/water (5:2:1), containing sorbitol ${ }^{13} \mathrm{C}_{6}$ at $2 \mathrm{mg} \mathrm{ml}^{-1}$ as internal standard, was added to the ground tissue. Samples were centrifuged at $3,000 \times g$ for $10 \mathrm{~min}$ at $4^{\circ} \mathrm{C}$ and supernatant containing metabolites was collected. Protein pellets were kept, subjected to phenol extraction, and stored at $-80^{\circ} \mathrm{C}$ until used for digestion and LC-MS/MS analyses. Metabolites were separated into polar and lipophilic phases by adding $2 \mathrm{ml}$ of distilled water. After vortexing and centrifugation (10 min, $3,000 \times g, 4^{\circ} \mathrm{C}$ ), aliquots of the polar phase were vacuum dried and stored at $-80^{\circ} \mathrm{C}$ until used for derivatization and GC-TOFMS analyses.

\section{Metabolite derivatization and GC-TOF-MS analysis.}

Samples were derivatized by dissolving the dried metabolite pellet in $20 \mu \mathrm{l}$ of methoxyamine hydrochloride $(40 \mathrm{mg} / \mathrm{ml} \mathrm{of}$ liquid pyridine) and shaking the mixture for $90 \mathrm{~min}$ at $30^{\circ} \mathrm{C}$. After addition of $90 \mu \mathrm{l}$ of N-methyl-N-(trimethylsilyl)trifluoroacetamide, the mixture was incubated at $37^{\circ} \mathrm{C}$ for $30 \mathrm{~min}$ with vigorous shaking. A mixture of internal retention index markers was prepared using even-numbered fatty acid methyl esters dissolved in chloroform at concentrations of $0.8 \mathrm{mg} \mathrm{ml}^{-1}$ and spiked into the derivatized sample.

GC-TOF-MS analysis was performed on an HP 5890 gas chromatograph with deactivated standard split/split-less liners containing glass wool (Agilent, Böblingen, Germany). Samples $(1 \mu \mathrm{l})$ were injected in the split-less mode at an injector temperature of $230^{\circ} \mathrm{C}$. The gas chromatograph was operated with a fused-silica MDN-35 capillary of 30-m length, 0.32$\mathrm{mm}$ internal diameter, and $0.25-\mu \mathrm{m}$ film thickness (Supelco, Bellefonte, PA, U.S.A.). Helium was used as carrier gas at a constant flow of $2 \mathrm{ml} \mathrm{min}{ }^{-1}$. The temperature program started with 2 min isocratic at $85^{\circ} \mathrm{C}$, followed by temperature ramping at $15^{\circ} \mathrm{C}$ per min to a final temperature of $360^{\circ} \mathrm{C}$, which was held for $8 \mathrm{~min}$. Data acquisition was performed on a Pegasus II TOF MS (Leco, St. Joseph, MI, U.S.A.) with an acquisition rate of 20 scans $\mathrm{s}^{-1}$ in the mass/charge $(\mathrm{m} / \mathrm{z})$ range of 85 to 600. The obtained data were first analyzed by defining a reference chromatogram with the maximum number of detected peaks over a signal/noise threshold of 50:1. Afterward, all chromatograms were matched against a reference library with a minimum match factor of 800 . Compounds were annotated by retention index and mass spectra comparison to a userdefined spectra library. Selected fragment ions specific for each individual metabolite were used for quantification. Because the concentration of sucrose and Asn was found to be above the linear measurement range, a second set of diluted samples was analyzed for a more accurate quantification. After automated mass spectra deconvolution and identification, data manual evaluation of the results was carried out. For metabolite validation, two criteria were followed: similarity to the fragmentation pattern in the mass spectra and retention time value within deviation limits. All known artifact or contaminant compounds were removed from the results table. Peak areas were normalized to internal standard values (sorbitol${ }^{13} \mathrm{C}_{6}$ ) and to nodule dry weight values.

\section{In-solution protein digestion.}

Digestion was carried out according to Washburn and associates (2001). Aliquots of protein samples were digested for 5 $h$ at $37^{\circ} \mathrm{C}$ with sequencing-grade endoproteinase Lys-C (1:100, 
vol/vol; Roche, Mannheim, Germany) in solubilization buffer containing $8 \mathrm{M}$ urea in $50 \mathrm{mM}$ Tris, $\mathrm{pH}$ 8. Samples were then diluted in buffer containing $10 \%$ ( $\mathrm{vol} / \mathrm{vol})$ acetonitrile, $0.1 \mathrm{M}$ $\mathrm{NH}_{4} \mathrm{HCO}_{3}$, and $1 \mathrm{mM} \mathrm{CaCl} 2(\mathrm{pH} \mathrm{8.5)}$ to an end concentration of $2 \mathrm{M}$ urea. Proteins were further digested overnight at $37^{\circ} \mathrm{C}$ with Porosyzme immobilized trypsin beads (1:10, vol/vol; Applied Biosystems, Darmstadt, Germany). After centrifugation for bead removal, the obtained peptide mixtures were desalted using SPEC C18 columns according to the manufacturer's instructions (Varian, Darmstadt, Germany). Finally, desalted digest solutions were concentrated down to a pellet such that they were not fully dried and pellets were subsequently stored at $-80^{\circ} \mathrm{C}$ until use.

\section{LC-MS/MS protein analysis.}

For relative protein quantification, and prior to MS measurements, protein digest pellets were dissolved in $0.5 \%$ ( $\mathrm{vol} / \mathrm{vol})$ formic acid. Digested samples $(200 \mu \mathrm{g})$ were loaded and concentrated on a precolumn (Agilent, Zeesen, Germany). Peptides were then loaded onto a $50-\mathrm{cm}$ silica-based $\mathrm{C} 18$ reversephase monolithic column (Merck, Darmstadt, Germany) with $100 \mu \mathrm{m}$ internal diameter. Peptide elution was carried out using a 2-h gradient from $100 \%$ solvent A (2.5\% [vol/vol] acetonitrile and $0.1 \%$ [vol/vol] formic acid in water) to $80 \%$ solvent B $(99.9 \%$ [vol $/ \mathrm{vol}]$ methanol and $0.1 \%$ [vol/vol] formic

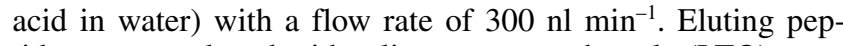
tides were analyzed with a linear trap quadrupole (LTQ) mass spectrometer (Thermo Electron, San Jose, CA, U.S.A.) operated in a data-dependent mode. Dynamic exclusion was not used. Each full MS scan was followed by five MS/MS scans, in which the five most abundant peptide molecular ions were dynamically selected for collision-induced dissociation using a normalized collision energy of $35 \%$. The temperature of the heated capillary and electrospray voltage were $150^{\circ} \mathrm{C}$ and 1.8 $\mathrm{kV}$, respectively.

For absolute protein quantification, internal standard peptides specific for each selected protein with an incorporated stable isotope $\left({ }^{13} \mathrm{C},{ }^{15} \mathrm{~N}\right)$ were synthesized (Thermo Electron, Ulm, Germany). Samples containing $50 \mu \mathrm{g}$ of nodule protein were trypsin digested in the presence of 1 pmol of each of the internal peptide standards. Absolute quantification was performed by comparing the peak area of the internal standard peptides with their corresponding native peptide as previously described (Wienkoop and Weckwerth 2006). Peptide sequences and specific single-reaction monitoring transition data for absolute quantification of the different nodule enzymes presented are described in detail by Wienkoop and associates (2008) For absolute quantification of the selected proteins, samples were loaded onto a $15-\mathrm{cm}$ silica-based $\mathrm{C} 18$ reverse-phase monolithic column (Merck) with a 100- $\mu$ m internal diameter coupled to a TSQ mass spectrometer (Thermo Electron). Peptides were eluted during a 30-min gradient from 5\% (vol/vol) methanol/ $0.1 \%$ (vol/vol) formic acid to $100 \%$ methanol $/ 0.1 \%$ formic

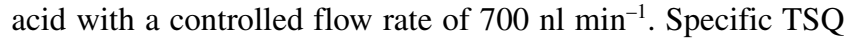
tune settings were spray voltage at $2.2 \mathrm{kV}$ and temperature of the heated transfer capillary at $150^{\circ} \mathrm{C}$.

\section{Protein identification.}

After MS analysis, DTA files were created from LTQ raw files and the obtained mass spectra were searched against a combined database integrating data from the Dana Farber Cancer Institute (DFCI) M. truncatula Gene Index 8.0 database and the protein database obtained from S. meliloti 1021 Genome Project using Bioworks 3.2. To create an accurate list of identified proteins with low false positive rates $(<1 \%)$, the software DTASelect (Tabb et al. 2002) was employed using the following criteria: normalized difference in correlation score of at least 0.08 and peptides with a +1 charge state were accepted if they had a cross correlation of at least 2.0, 1.6 for +2 charge state peptides, and larger than 3 for +3 charged peptides, with at least two different peptides identified per protein. A variable modification of Met oxidation was allowed. These stringent criteria were employed in order to benefit the accuracy and reliability of the method rather than maximizing the number of identified proteins. For relative quantification, the cumulative sum of recorded peptides per protein, called spectral count, was used as previously described (Larrainzar et al. 2007).

\section{Statistical analysis.}

For data mining and visualization of results, metabolomic and proteomic data sets were normalized and $\log _{10}$ transformed. HCL was carried out using the TIGR Multiexperiment Viewer software included in the TM4 suite. Clustering was carried out using the Euclidean distance and complete linkage method. ICA was performed using the MetaGeneAlyse server. PCA was applied as a preprocessing step for dimensionality reduction to a set of three principal components and visualization of relevant variances. ICA was then applied to this reduced data set for the evaluation of those covariant protein or metabolite sets that were involved in the response to water deficit and recovery according to Scholz and Selbig (2007).

Detailed analysis of the metabolite and protein datasets was performed by calculating the ratios between control and treated samples at different time points. Using daily control plants allowed for the minimization of development-related variations in nodules. Significant differences between these were determined using Student's $t$ test at $\alpha=0.05$.

\section{ACKNOWLEDGMENTS}

This work was supported by the Ministry of Science and Innovation (Spain, grant no. AGL2008-00069/AGR), the European Commission (Grain Legumes, grant no. FOOD-CT-2004-506223) and by the Government of Navarre (grant no. 228/2008). We thank Ä. Eckardt (Willmitzer's group, Max Planck Institute of Molecular Plant Physiology, Potsdam, Germany) for the GC-TOF-MS metabolite measurements, F. Minchin for helpful comments on the manuscript, G. Garijo for technical assistance, and J. Aldasoro and A. Ederra for help in plant cultivation and material harvesting.

\section{LITERATURE CITED}

Anthon, G. E., and Emerich, D. W. 1990. Developmental regulation of enzymes of sucrose and hexose metabolism in effective and ineffective soybean nodules. Plant Physiol. 92:346-351.

Arrese-Igor, C., González, E. M., Gordon, A. J., Minchin, F. R., Gálvez, L., Royuela, M., Cabrerizo, P. M., and Aparicio-Tejo, P. M. 1999. Sucrose synthase and nodule nitrogen fixation under drought and other environmental stresses. Symbiosis 27:189-212.

Atkins, C. A., Fernando, M., Hunt, S., and Layzell, D. B. 1992. A metabolic connection between nitrogenase activity and the synthesis of ureides in nodulated soybean. Physiol. Plant. 84:441-447.

Bacanamwo, M., and Harper, J. E. 1997. The feedback mechanism of nitrate inhibition of nitrogenase activity in soybean may involve asparagine and/or products of its metabolism. Physiol. Plant. 100:371-377.

Baier, M. C., Barsch, A., Kuster, H., and Hohnjec, N. 2007. Antisense repression of the Medicago truncatula nodule-enhanced sucrose synthase leads to a handicapped nitrogen fixation mirrored by specific alterations in the symbiotic transcriptome and metabolome. Plant Physiol. 145:1600-1618.

Bestel-Corre, G., Dumas-Gaudot, E., Poinsot, V., Dieu, M., Dierick, J. F., Van, T. D., Remacle, J., Gianinazzi-Pearson, V., and Gianinazzi, S. 2002. Proteome analysis and identification of symbiosis-related proteins from Medicago truncatula Gaertn. by two-dimensional electrophoresis and mass spectrometry. Electrophoresis 23:122-137.

Carvalho, H., Lescure, N., de Billy, F., Chabaud, M., Lima, L., Salema, R., and Cullimore, J. 2000. Cellular expression and regulation of the Medicago truncatula cytosolic glutamine synthetase genes in root nodules. Plant Mol. Biol. 42:741-756.

Catalano, C. M., Lane, W. S., and Sherrier, D. J. 2004. Biochemical char- 
acterization of symbiosome membrane proteins from Medicago truncatula root nodules. Electrophoresis 25:519-531.

Craig, J., Barratt, P., Tatge, H., Dejardin, A., Handley, L., Gardner, C. D., Barber, L., Wang, T., Hedley, C., Martin, C., and Smith, A. M. 1999. Mutations at the rug4 locus alter the carbon and nitrogen metabolism of pea plants through an effect on sucrose synthase. Plant J. 17:353-362.

Daub, C. O., Kloska, S., and Selbig, J. 2003. MetaGeneAlyse: Analysis of integrated transcriptional and metabolite data. Bioinformatics 19:23322333

Davey, A. G., and Simpson, R. J. 1990. Nitrogen fixation by subterranean clover at varying stages of nodule dehydration. 1. Carbohydrate status and short-term recovery of nodulated root respiration. J. Exp. Bot. 41:1175-1187.

Degenkolbe, T., Do, P. T., Zuther, E., Repsilber, D., Walther, D., Hincha D. K., and Kohl, K. I. 2009. Expression profiling of rice cultivars differing in their tolerance to long-term drought stress. Plant Mol. Biol. 69:133-153

Del Castillo, L. D., and Layzell, D. B. 1995. Drought stress, permeability to $\mathrm{O}_{2}$ diffusion, and the respiratory kinetics of soybean root nodules. Plant Physiol. 107:1187-1194.

Del Castillo, L. D., Hunt, S., and Layzell, D. B. 1994. The role of oxygen in the regulation of nitrogenase activity in drought-stressed soybean nodules. Plant Physiol. 106:949-955.

Denison, R. F. 1998. Decreased oxygen permeability: A universal stress response in legume root nodules. Bot. Acta. 111:191-192.

Djordjevic, M. A., Chen, H. C., Natera, S., Van Noorden, G., Menzel, C., Taylor, S., Renard, C., Geiger, O., Weiller, G. F., and Sinorhizobium DNA Sequencing Consortium. 2003. A global analysis of protein expression profiles in Sinorhizobium meliloti: Discovery of new genes for nodule occupancy and stress adaptation. Mol. Plant-Microbe Interact. 16:508-524.

Durand, J. L., Sheehy, J. E., and Minchin, F. R. 1987. Nitrogenase activity, photosynthesis and nodule water potential in soybean plants experiencing water deprivation. J. Exp. Bot. 38:311-321.

Edgren, T., and Nordlund, S. 2004. The fixABCX genes in Rhodospirillum rubrum encode a putative membrane complex participating in electron transfer to nitrogenase. J. Bacteriol. 186:2052-2060.

El Yahyaoui, F., Küster, H., Amor, B. B., Hohnjec, N., Pühler, A., Becker, A., Gouzy, J., Vernie, T., Gough, C., Niebel, A., Godiard, L., and Gamas, P. 2004. Expression profiling in Medicago truncatula identifies more than 750 genes differentially expressed during nodulation, including many potential regulators of the symbiotic program. Plant Physiol. 136:3159-3176

Evans, H. J. 1981. Symbiotic nitrogen fixation in legume nodules. In: Research Experiences in Plant Physiology. T. C. Moore, ed. SpringerVerlag, New York.

Fellows, R. J., Patterson, R. P., Raper, C. D., and Harris, D. 1987. Nodule activity and allocation of photosynthate of soybean during recovery from water stress. Plant Physiol. 84:456-460.

Fiehn, O., Sumner, L. W., Rhee, S. Y., Ward, J., Dickerson, J., Lange, B. M., Lane, G., Roessner, U., Last, R., and Nikolau, B. 2007. Minimum reporting standards for plant biology context information in metabolomic studies. Metabolomics 3:195-201.

Fiehn, O., Wohlgemuth, G., Scholz, M., Kind, T., Lee do, Y., Lu, Y., Moon, S., and Nikolau, B. 2008. Quality control for plant metabolomics: Reporting MSI-compliant studies. Plant J. 53:691-704.

Fougere, F., Le Rudulier, D., and Streeter, J. G. 1991. Effects of salt stress on amino acid, organic acid, and carbohydrate composition of roots, bacteroids, and cytosol of alfalfa (Medicago sativa L.). Plant Physiol. 96:1228-1236.

Gallardo, K., Le Signor, C., Vandekerckhove, J., Thompson, R. D., and Burstin, J. 2003. Proteomics of Medicago truncatula seed developmen establishes the time frame of diverse metabolic processes related to reserve accumulation. Plant Physiol. 133:664-682.

Gálvez, L., González, E. M., and Arrese-Igor, C. 2005. Evidence for carbon flux shortage and strong carbon/nitrogen interactions in pea nodules at early stages of water stress. J. Exp. Bot. 56:2551-2561.

González, E. M., Gordon, A. J., James, C. L., and Arrese-Igor, C. 1995. The role of sucrose synthase in the response of soybean nodules to drought. J. Exp. Bot. 46:1515-1523.

González, E. M., Aparicio-Tejo, P. M., Gordon, A. J., Minchin, F. R., Royuela, M., and Arrese-Igor, C. 1998. Water-deficit effects on carbon and nitrogen metabolism of pea nodules. J. Exp. Bot. 49:1705-1714.

Gordon, A. J., Minchin, F. R., Skot, L., and James, C. L. 1997. Stressinduced declines in soybean $\mathrm{N}_{2}$ fixation are related to nodule sucrose synthase activity. Plant Physiol. 114:937-946.

Gordon, A. J., Minchin, F. R., James, C. L., and Komina, O. 1999. Sucrose synthase in legume nodules is essential for nitrogen fixation. Plant Physiol. 120:867-877.

Graham, P. H., and Vance, C. P. 2003. Legumes: Importance and con- straints to greater use. Plant Physiol. 131:872-877.

Groat, R. G., and Vance, C. P. 1981. Root nodule enzymes of ammonia assimilation in alfalfa (Medicago sativa $\mathrm{L}$ ). Developmental patterns and response to applied nitrogen. Plant Physiol. 67:1198-1203.

Hohnjec, N., Perlick, A. M., Puhler, A., and Kuster, H. 2003. Medicago truncatula sucrose synthase gene MtSucS1 is activated both in the infected region of root nodules and in the cortex of roots colonized by arbuscular mycorrhizal fungi. Mol. Plant-Microbe Interact. 16:903-915.

Horst, I., Welham, T., Kelly, S., Kaneko, T., Sato, S., Tabata, S., Parniske, M., and Wang, T. L. 2007. TILLING mutants of Lotus japonicus reveal that nitrogen assimilation and fixation can occur in the absence of nodule-enhanced sucrose synthase. Plant Physiol. 144:806-820.

Hummel, J., Niemann, M., Wienkoop, S., Schulze, W., Steinhauser, D., Selbig, J., Walther, D., and Weckwerth, W. 2007. ProMEX: A mass spectral reference database for proteins and protein phosphorylation sites. BMC Bioinf. 8:216.

Hunt, S., and Layzell, D. B. 1993. Gas exchange of legume nodules and the regulation of nitrogenase activity. Annu. Rev. Plant Physiol. Plant Mol. Biol. 44:483-511.

King, C. A., and Purcell, L. C. 2005. Inhibition of $\mathrm{N}_{2}$ fixation in soybean is associated with elevated ureides and amino acids. Plant Physiol. 137:1389-1396.

Ladrera, R., Marino, D., Larrainzar, E., González, E. M., and Arrese-Igor, C. 2007. Reduced carbon availability to bacteroids and elevated ureides in nodules, but not in shoots, are involved in the nitrogen fixation response to early drought in soybean. Plant Physiol. 145:539-546.

Larrainzar, E., Wienkoop, S., Weckwerth, W., Ladrera, R., Arrese-Igor, C., and González, E. M. 2007. Medicago truncatula root nodule proteome analysis reveals differential plant and bacteroid responses to drought stress. Plant Physiol. 144:1495-1507.

Lehmann, U., Wienkoop, S., Tschoep, H., and Weckwerth, W. 2008. If the antibody fails - a mass western approach. Plant J. 55:1039-1046.

Lima, L., Seabra, A., Melo, P., Cullimore, J., and Carvalho, H. 2006. Posttranslational regulation of cytosolic glutamine synthetase of Medicago truncatula. J. Exp. Bot. 57:2751-2761.

Liu, H., Sadygov, R. G., and Yates, J. R., 3rd. 2004. A model for random sampling and estimation of relative protein abundance in shotgun proteomics. Anal. Chem. 76:4193-4201.

Marino, D., Frendo, P., Ladrera, R., Zabalza, A., Puppo, A., Arrese-Igor, C., and González, E. M. 2007. Nitrogen fixation control under drought stress. Localized or systemic? Plant Physiol. 143:1968-1974.

Mathesius, U., Keijzers, G., Natera, S. H. A., Weinman, J. J., Djordjevic, M. A., and Rolfe, B. G. 2001. Establishment of a root proteome reference map for the model legume Medicago truncatula using the expressed sequence tag database for peptide mass fingerprinting. Proteomics 1:1424-1440.

Morgenthal, K., Wienkoop, S., Wolschin, F., and Weckwerth, W. 2007. Integrative profiling of metabolites and proteins: Improving pattern recognition and biomarker selection for systems level approaches. Methods Mol. Biol. 358:57-75.

Muller, J., Boller, T., and Wiemken, A. 1996. Pools of non-structural carbohydrates in soybean root nodules during water stress. Physiol. Plant. 98:723-730.

Natera, S. H., Guerreiro, N., and Djordjevic, M. A. 2000. Proteome analysis of differentially displayed proteins as a tool for the investigation of symbiosis. Mol. Plant-Microbe Interact. 13:995-1009.

Naya, L., Ladrera, R., Ramos, J., González, E. M., Arrese-Igor, C., Minchin, F. R., and Becana, M. 2007. The response of carbon metabolism and antioxidant defenses of alfalfa nodules to drought stress and to the subsequent recovery of plants. Plant Physiol. 144:11041114

Neo, H. H., and Layzell, D. B. 1997. Phloem glutamine and the regulation of $\mathrm{O}_{2}$ diffusion in legume nodules. Plant Physiol. 113:259-267.

Pradet, A., and Raymond, P. 1983. Adenine nucleotide ratios and adenylate energy-charge in energy metabolism. Annu. Rev. Plant Physiol. Plant Mol. Biol. 34:199-224.

Ramos, M. L. G., Gordon, A. J., Minchin, F. R., Sprent, J. I., and Parsons, R. 1999. Effect of water stress on nodule physiology and biochemistry of a drought tolerant cultivar of common bean (Phaseolus vulgaris L.). Ann. Bot. 83:57-63.

Roy-Macauley, H., Zuily-Fodil, Y., Kidric, M., Thi, A. T. P., and Dasilva, J. V. 1992. Effect of drought stress on proteolytic activities in Phaseolus and Vigna leaves from sensitive and resistant plants. Physiol. Plant. 85:90-96

Scholz, M., and Selbig, J. 2007. Visualization and analysis of molecular data. Methods Mol. Biol. 358:87-104.

Schubert, S., Serraj, R., Pliesbalzer, E., and Mengel, K. 1995. Effect of drought stress on growth, sugar concentrations and amino-acid accumulation in $\mathrm{N}_{2}$-fixing alfalfa (Medicago sativa). J. Plant Physiol. 146:541546. 
Serraj, R., Shelp, B. J., and Sinclair, T. R. 1998. Accumulation of gammaaminobutyric acid in nodulated soybean in response to drought stress. Physiol. Plant. 102:79-86.

Serraj, R., Vadez, V., Denison, R. F., and Sinclair, T. R. 1999. Involvement of ureides in nitrogen fixation inhibition in soybean. Plant Physiol. 119:289-296.

Shi, L. F., Twary, S. N., Yoshioka, H., Gregerson, R. G., Miller, S. S. Samac, D. A., Gantt, J. S., Unkefer, P. J., and Vance, C. P. 1997. Nitrogen assimilation in alfalfa: Isolation and characterization of an asparagine synthetase gene showing enhanced expression in root nodules and dark-adapted leaves. Plant Cell 9:1339-1356.

Sperotto, R. A., Gross, J., Vedoy, C., Passaglia, L. M., and Schrank, I. S. 2004. The electron transfer flavoprotein fixABCX gene products from Azospirillum brasilense show a NifA-dependent promoter regulation. Curr. Microbiol. 49:267-273.

Sprent, J. I. 2001. Nodulation in legumes. Royal Botanic Gardens, Kew, U.K.

Streeter, J. G. 1987. Carbohydrate, organic acid, and amino acid composition of bacteroids and cytosol from soybean nodules. Plant Physiol. 85:768-773.

Sumner, L. W., Amberg, A., Barrett, D., Beale, M. H., Beger, R., Daykin, C. A., Fan, T. W. M., Fiehn, O., Goodacre, R., Griffin, J. L., Hankemeier, T., Hardy, N., Harnly, J., Higashi, R., Kopka, J., Lane, A. N., Lindon, J. C., Marriott, P., Nicholls, A. W., Reily, M. D., Thaden, J. J., and Viant, M. R. 2007. Proposed minimum reporting standards for chemical analysis. Metabolomics 3:211-221.

Tabb, D. L., McDonald, W. H., and Yates, J. R., 3rd. 2002. DTASelect and Contrast: Tools for assembling and comparing protein identifications from shotgun proteomics. J. Proteome Res. 1:21-26.

Torres-Franklin, M. L., Gigon, A., de Melo, D. F., Zuily-Fodil, Y., and Pham-Thi, A. T. 2007. Drought stress and rehydration affect the balance between MGDG and DGDG synthesis in cowpea leaves. Physiol. Plant. 131:201-210.

Vadez, V., Sinclair, T. R., and Serraj, R. 2000. Asparagine and ureide accumulation in nodules and shoots as feedback inhibitors of $\mathrm{N}_{2}$ fixation in soybean. Physiol. Plant. 110:215-223.

Valot, B., Gianinazzi, S., and Dumas-Gaudot, E. 2004. Sub-cellular proteomic analysis of a Medicago truncatula root microsomal fraction. Phytochemistry 65:1721-1732.

Van den Ende, W., and Valluru, R. 2009. Sucrose, sucrosyl oligosaccha- rides, and oxidative stress: Scavenging and salvaging? J. Exp. Bot. 60:9-18.

Venkateswarlu, B., Saharan, N., and Maheswari, M. 1990. Nodulation and $\mathrm{N}_{2}\left(\mathrm{C}_{2} \mathrm{H}_{2}\right)$ fixation in cowpea and groundnut during water stress and recovery. Field Crops Res. 25:223-232.

Washburn, M. P., Wolters, D., and Yates, J. R., 3rd. 2001. Large-scale analysis of the yeast proteome by multidimensional protein identification technology. Nat. Biotechnol. 19:242-247.

Watson, B. S., Asirvatham, V. S., Wang, L., and Sumner, L. W. 2003. Mapping the proteome of barrel medic (Medicago truncatula). Plant Physiol. 131:1104-1123.

Wienkoop, S., and Weckwerth, W. 2006. Relative and absolute quantitative shotgun proteomics: Targeting low-abundance proteins in Arabidopsis thaliana. J. Exp. Bot. 57:1529-1535.

Wienkoop, S., Larrainzar, E., Niemann, M., González, E. M., Lehmann, U., and Weckwerth, W. 2006. Stable isotope-free quantitative shotgun proteomics combined with sample pattern recognition for rapid diagnostics. J. Sep. Sci. 29:2793-2801.

Wienkoop, S., Larrainzar, E., Glinski, M., González, E. M., Arrese-Igor, C., and Weckwerth, W. 2008. Absolute quantification of Medicago truncatula sucrose synthase isoforms and $\mathrm{N}$-metabolism enzymes in symbiotic root nodules and the detection of novel nodule phosphoproteins by mass spectrometry. J. Exp. Bot. 59:3307-3315.

Witty, J. F., and Minchin, F. R. 1998. Methods for the continuous measurement of $\mathrm{O}_{2}$ consumption and $\mathrm{H}_{2}$ production by nodulated legume root systems. J. Exp. Bot. 49:1041-1047.

Zahran, H. H. 1999. Rhizobium-legume symbiosis and nitrogen fixation under severe conditions and in an arid climate. Microbiol. Mol. Biol. Rev. 63:968-989.

\section{AUTHOR-RECOMMENDED INTERNET RESOURCES}

DFCI Medicago Gene Index webpage: compbio.dfci.harvard.edu/tgi

MetaGeneAlyse server: metagenealyse.mpimp-golm.mpg.de

Protein Mass Spectra Extraction database (PROMEX): promex.mpimpgolm.mpg.de (moved to www.promexdb.org)

S. meliloti 1021 Genome database: iant.toulouse.inra.fr/bacteria/annotation/cgi/rhime.cgi

TIGR Multiexperiment Viewer software: www.tm4.org/mev.htm 